\title{
Small heat-shock protein Hsp12 contributes to yeast tolerance to freezing stress
}

Correspondence

M. J. Sousa

mjsousa@bio.uminho.pt

Received 17 November 2008

Revised 11 March 2009

Accepted 12 March 2009

\author{
A. Pacheco, C. Pereira, M. J. Almeida and M. J. Sousa
} CBMA (Centre of Molecular and Environmental Biology), Department of Biology, University of
Minho, Campus of Gualtar, 4710-057 Braga, Portugal

\section{INTRODUCTION}

Because freezing is one of the major abiotic stresses, the adaptation mechanisms that preserve cells at subzero temperatures are extremely important in the development of technology for the cryopreservation of life. Preservation of cell activity is also a very important issue in frozendough technology. This process is well established in the modern baking industry, as it can more easily supply ovenfresh bakery products to consumers while improving labour conditions. Nevertheless, storage of frozen bread dough may lead to the loss of cell viability of baker's yeast as well as of its baking capacity, and consequently to economic losses (Alves-Araújo et al., 2004; Randez-Gil et al., 1999). In spite of their importance, limited information is available about the mechanisms and determinants of freezing resistance and cold responses in yeast (Kandror \& Goldberg, 1997; Kandror et al., 2004; Odani et al., 2003; Zarka et al., 2003). When yeast cells are cultured at $4{ }^{\circ} \mathrm{C}$ for a long period, several heat-shock proteins (HSPs) are induced (Homma et al., 2003), suggesting that the induction of these genes might be necessary for adjustment to cold resistance. Considerable evidence indicates that the intracellular level of trehalose may determine the survival response of yeasts under

Abbreviations: HSP, heat-shock protein; LEA, late embryogenesis abundant; PI, propidium iodide; RE, relative expression. extreme environmental conditions (Diniz-Mendes et al., 1999; Hottiger et al., 1987; Singer \& Lindquist, 1998; Van Dijck et al., 1995; Wiemken, 1990). In general, there is wide consensus that trehalose can serve as a stress protectant when yeast cells are confronted with high or low temperatures (Attfield, 1987; Hottiger et al., 1987). Nevertheless, no direct correlation was observed between trehalose accumulation and freezing resistance, above a certain intracellular concentration (Alves-Araújo et al., 2004).

In plants, LEA (late embyrogenesis abundant)-like proteins have been described to play a role in the cold acclimation process and their expression and accumulation is increased in response to cold and freezing temperatures (Borovskii et al., 2002; NDong et al., 2002). In yeast these proteins also seem to contribute to stress tolerance, since heterologous expression of tomato, wheat and barley LEA proteins conferred increased resistance to osmotic or freeze stresses (Zhang et al., 2000). Small heat-shock protein 12 (Hsp12) has been described as a LEA-like protein in Saccharomyces cerevisiae (Mtwisha et al., 1998) and it has been reported to be localized both at the plasma membrane, protecting membranes from desiccation (Sales et al., 2000), and in the cytoplasm and cell wall, enhancing barotolerance of the yeast (Motshwene et al., 2004). HSP12 is induced massively in yeast cells exposed to heat shock, osmostress, oxidative stress or high concentrations of alcohol, as well as in early 
stationary-phase cells (Praekelt \& Meacock, 1990; Stone et al., 1990). It is also induced at $0{ }^{\circ} \mathrm{C}$ as part of the nearfreezing response (Kandror et al., 2004) and by $4{ }^{\circ} \mathrm{C}$ exposure (Murata et al., 2006). However, to date few studies could demonstrate any correlation between HSP12 disruption or overexpression and a phenotype of sensitivity/resistance, making it difficult to attribute a role for Hsp12p under most of these stress conditions. In this study we investigated the possible role of Hsp $12 \mathrm{p}$ in freezing tolerance, using the yeast $S$. cerevisiae as a model. We report here that Hsp12p plays a role in cryoresistance, even though the hsp12 null mutant was revealed to be more resistant to freezing than the wild-type strain. We also show that stationary-phase cells of the $h s p 12 \Delta$ mutant have a higher intracellular trehalose concentration than wildtype cells, even though heat-induced trehalose accumulation is impaired in this mutant. Overexpression of HSP 12 in a $t p s 1 \Delta$ strain allowed us to demonstrate a clear increase in resistance to freezing storage and also to heat stress.

\section{METHODS}

Strains. The Saccharomyces cerevisiae BY4742 wild-type strain and isogenic mutants used in this study are listed in Table 1. The plasmid vector pRS $41 \mathrm{H}$ (Taxis \& Knop, 2006) was kindly provided by Christof Taxis and Michael Knop from the EMBL Cell Biology and Biophysics Unit, Heidelberg, Germany.

Media and growth conditions. YPD (1\% yeast extract, $2 \%$ Bactopeptone, and $2 \%$ glucose) and LB medium were prepared as previously described (Sambrook et al., 1989). For the selection of $h p h N T 1,300 \mathrm{mg}$ hygromycin B $1^{-1}$ was added to standard YPD plates or liquid YPD medium after autoclaving and cooling to $60{ }^{\circ} \mathrm{C}$ (Duchefa Biochemie). The hygromycin B stock solution was used as provided by the manufacturer. When necessary, $100 \mu \mathrm{g}$ ampicillin $\mathrm{ml}^{-1}$ was added to standard LB plates or liquid medium, after autoclaving and cooling to $60{ }^{\circ} \mathrm{C}$. A sterile filtered stock solution was used in this case. Yeast cells were routinely grown on YPD medium at $30{ }^{\circ} \mathrm{C}$ and 200 r.p.m.

Reagents. Oligonucleotides $(0.05 \mu \mathrm{mol}$ scale $)$ were purchased from MWG Biotech. Restriction and modification enzymes were from Roche Applied Science. Accuzyme DNA Polymerase was obtained from Bioline.

Plasmid construction. The HSP12 gene sequence was PCRamplified with the primers Hsp12Fw (5'-GATCGGATCCAAATGTCTGACGCAGGTAGAAAAGG-3') and Hsp12Rev (5'-GATCGTCGACTTACTTCTTGGTTGGGTCTTCTT-3') from genomic DNA of S. cerevisiae BY4742. The PCR protocol involved an initial denaturation at $94{ }^{\circ} \mathrm{C}(5 \mathrm{~min})$, followed by 30 cycles of $30 \mathrm{~s}$ at $94{ }^{\circ} \mathrm{C}$, $30 \mathrm{~s}$ at $55^{\circ} \mathrm{C}$ and $1 \mathrm{~min}$ at $72{ }^{\circ} \mathrm{C}$. The last cycle was followed by a final extension step of $10 \mathrm{~min}$ at $72{ }^{\circ} \mathrm{C}$. About $100 \mathrm{ng}$ DNA template was used in a $50 \mu \mathrm{l}$ reaction mixture. The $300 \mathrm{bp}$ PCR product was cloned into pGEM T-easy cloning vector (Promega). The EcoRIrestricted fragment was then cloned into the EcoRI-restricted and dephosphorylated p426GPD vector (Mumberg et al., 1995). The 1240 bp KpnI-GPD promoter-HSP12-CYC terminator-SacI fragment was subcloned on pRS41H centromeric plasmid vector, creating pRSHSP12, which contains the HSP12 gene under the regulation of the $S$. cerevisiae GPD promoter from p426GPD. DNA fragments resolved in agarose gels were purified by use of a QIAquick gel extraction kit (Qiagen).

\section{Transformation and DNA sequencing}

E. coli transformation. All the vectors constructed were first established in E. coli XL1-Blue, according to the 'SEM' method (Inoue et al., 1990). The correct plasmid constructs were verified by restriction map analysis followed by DNA sequencing with an ABI PRISM 310 Genetic Analyzer, using the method of Sanger \& Coulson (1975).

Yeast transformation. All yeast transformations were performed using the lithium acetate protocol as previously described (Schiestl \& Gietz, 1989). Correct yeast transformations were verified by plasmid DNA isolation using the ChargesSwitch plasmid yeast mini kit (Invitrogen) and subsequent transformation in E. coli according to the 'SEM' method. DNA cloning and manipulation were performed according to the standard protocols as described by Sambrook et al. (1989).

Yeast freezing. Freezing assays were performed as previously described (Alves-Araújo et al., 2004) with minor changes. Stationary-phase cells $(25 \mathrm{ml}$ of $24 \mathrm{~h}$ culture) were washed twice with deionized water and suspended in a quarter of the initial volume in sterile water. Aliquots $(500 \mu \mathrm{l})$ of cells were transferred into $1.5 \mathrm{ml}$ tubes, centrifuged and the pellet suspended in $100 \mu \mathrm{LF}$ (liquid fermentation) medium (Hino et al., 1990). The samples were frozen at $-20{ }^{\circ} \mathrm{C}$ for different time periods.

Extraction and assay of trehalose. Trehalose extraction was performed for the yeast suspensions prepared as described above, immediately before freezing, and sampled for dry weight. Cells were harvested by centrifugation and washed twice with cold deionized water. Trehalose was extracted from cold cell pellets with $5 \%(\mathrm{w} / \mathrm{v})$ trichloroacetic acid (Merck) for $45 \mathrm{~min}$ with occasional shaking. Cells were then centrifuged at $735 \mathrm{~g}$ for $10 \mathrm{~min}$. Extraction was repeated once more, and supernatants from the two extractions were combined and used for the determination of trehalose by HPLC. The apparatus used was a Gilson chromatograph (132-RI Detector), equipped with a carbohydrate $\mathrm{H}^{+}$column (SS-100, $\mathrm{H}^{+}$, Hypersil) that was main-

Table 1. S. cerevisiae strains used in this study

\begin{tabular}{|c|c|c|}
\hline Strain & Genotype & Source \\
\hline BY4742 (wt) & $M A T \alpha ;$ his $3 \Delta 1 ;$ leu $2 \Delta 0 ;$ lys $2 \Delta 0 ;$ ura $3 \Delta 0$ & EUROSCARF \\
\hline 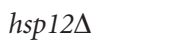 & BY4742; YFL014w : : kanMX4 & EUROSCARF \\
\hline$t p s 1 \Delta$ & BY4742; YBR126c:: kanMX4 & EUROSCARF \\
\hline$d u r 1,2 \Delta$ & BY4742; YBR208c: : kanMX4 & EUROSCARF \\
\hline$t p s 1 \Delta-\mathrm{p}_{\mathrm{empty}}$ & $t p s 1 \Delta$-pRS41H & This study \\
\hline$t p s 1 \Delta-\mathrm{p}_{\mathrm{HSP} 12}$ & tps1D-pRSHSP12 & This study \\
\hline
\end{tabular}


tained at $60{ }^{\circ} \mathrm{C}$. A solution of $\mathrm{H}_{2} \mathrm{SO}_{4}(0.0025 \mathrm{M})$ was used as the

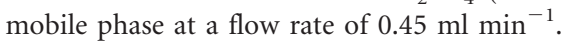

Measurement of cell viability. Cell viability was analysed by flow cytometry using the membrane exclusion dye propidium iodide (PI), as previously described (Alves-Araújo et al., 2004). In these assays, cells with conserved membrane integrity are not permeated by PI ( $\mathrm{PI}^{-}$cells), while those that have lost their membrane integrity do incorporate the fluorochrome ( $\mathrm{PI}^{+}$cells) (Prudencio et al., 1998). Previous results showed that in cells subjected to freezing stress, the loss of cell proliferative capacity (expressed as c.f.u. counts) perfectly correlates with loss of membrane integrity (Alves-Araújo et al., 2004).

Expression analysis by quantitative real-time PCR. Relative expression (RE) was calculated as $2-\left[\left(\right.\right.$ gene of interest $\left.\Delta C_{\mathrm{t}}\right)-\left(\right.$ calibrator $\left.\left.\Delta C_{\mathrm{t}}\right)\right] . \Delta C_{\mathrm{t}}$ was calculated as (sample $C_{\mathrm{t}}$ )-(housekeeping gene $18 \mathrm{~S} C_{\mathrm{t}}$ ). The $C_{\mathrm{t}}$ values of both the calibrator and the samples of interest were normalized to the endogenous housekeeping $18 \mathrm{~S}$ rRNA gene. Target gene expression was considered increased if relative expression was $>1$, once values of $\mathrm{RE}$ in each experiment were normalized with respect to the calibrator sample, with a RE value set to 1 . Both actin (ACT1) and $18 \mathrm{~S}$ rRNA gene transcript levels were used to control for amount of RNA. We have found the mRNA of the 18S rRNA gene to be a better control, since the levels of actin mRNA were less constant in cells, as already described by others (Seymour \& Piper, 1999; Wenzel et al., 1995).

Reproducibility of the results. All the experiments were repeated at least three times, and the data reported are mean values \pm SD. When statistical analyses were performed, the significance was tested by ANOVA and $t$-test (GraphPad Prism 5).

\section{RESULTS}

\section{The hsp12 $\Delta$ strain is more resistant to freezing at $-20{ }^{\circ} \mathrm{C}$ than the wild-type strain}

Aiming at the investigation of the possible role of Hsp12p in yeast freezing tolerance, we subjected stationary-phase cells of S. cerevisiae BY4742 (wild-type) and of a hsp12deleted isogenic strain to prolonged storage at $-20{ }^{\circ} \mathrm{C}$. Since we have previously shown that in cells subjected to freezing stress, loss of cell proliferative capacity perfectly correlated with the loss of membrane integrity (AlvesAraújo et al., 2004), viability of the cells during freezing was assessed by flow cytometry using the fluorochrome PI. In both strains, we analysed cell viability for a storage period of 8 days. Contrary to what would be expected taking into account that HSP12 is highly induced by cold stress (Kandror et al., 2004; Murata et al., 2006), viability loss during freezing storage at $-20{ }^{\circ} \mathrm{C}$ was lower for the $h s p 12$ null mutant than for the wild-type strain (Fig. 1a). A decrease of $80 \%$ in cell viability was observed for the wildtype strain after 8 days storage, whereas the $h s p 12 \Delta$ strain showed a loss in cell viability of only about $40 \%$ after the same period, indicating that the absence of Hsp12p resulted in a higher resistance to freezing. To further support that the observed differences were due to absence/ presence of Hsp12p in the cells, the same experiments were performed with cells harvested in the exponential growth phase. At this culture stage, HSP12 expression is repressed. As a consequence, Hsp12p is absent or vestigial in both
hsp12A and wild-type strains (Praekelt \& Meacock, 1990). As expected, the two strains showed a similar behaviour, no significant differences being observed in freezing resistance at $-20{ }^{\circ} \mathrm{C}$ (Fig. 1b).

\section{The HSP12 deletion strain displays an increase in intracellular trehalose content}

Trehalose is widely recognized as one of the most effective compounds in the protection of cellular structures against the damage caused by freezing. The accumulation of trehalose in fungi is associated in general with periods of starvation and reduced growth rate (Kuenzi \& Fiechter, 1972; Lillie \& Pringle, 1980; Panek, 1975). For our freezing experiments, cells were harvested in stationary phase, when trehalose synthesis is particularly intensive (Kuenzi \& Fiechter, 1972; Lillie \& Pringle, 1980; Panek, 1975). In addition, it has been previously described that another HSPdisrupted strain, $h s p 104 \Delta$, displayed increased intracellular trehalose concentrations (Fujita et al., 1998). In order to ascertain if the $h s p 12 \Delta$ mutant, similarly to $h s p 104 \Delta$, could have an increase in intracellular trehalose concentration, which could be masking any freezing sensitivity caused by HSP12 deletion, we assessed the trehalose content of this strain. The results showed that when compared to the wildtype strain, the $h s p 12 \Delta$ mutant presented a $50 \%$ higher intracellular trehalose concentration (Table 2). We further confirmed that this increase in trehalose content was specific for the disruption of the HSP12 gene, since no differences in the trehalose content were observed for the same wild-type

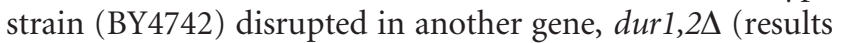
not shown). The results supported our hypothesis that an increase in intracellular trehalose concentration could be responsible for the higher freezing resistance observed, not allowing differentiation of the possible effects of HSP12 deletion. In addition, they suggest that under these circumstances trehalose may in fact be more critical for survival than Hsp12p, as reported by some other authors (Hottiger et al., 1989; Kandror et al., 2002), or at least it may replace the functions of Hsp12p.

\section{Hsp12p contributes to yeast freezing resistance}

We next wanted to check whether the overexpression of HSP12 might also have an effect on freezing tolerance. The fact that HSPs and trehalose both contribute to yeast stress tolerance (Iwahashi et al., 1997; Sales et al., 2000) is an obstacle to the assessment of their individual role in the acquisition of freezing tolerance by cells. To be able to evaluate any effect of HSP12 overexpression, minimizing trehalose influence, we used a trehalose-6-phosphate synthase TPS1 null mutant, lacking the enzyme trehalose6-phosphate synthase, which is responsible for the first step in trehalose synthesis. Mutations in the TPS1 gene are reported to result in lack of ability to synthesize trehalose. Nevertheless, since previous studies (Plourde-Owobi et al., 1999, 2000), and more recently Jules et al. (2008), reported that accumulation of trehalose may arise from the active 
(a)

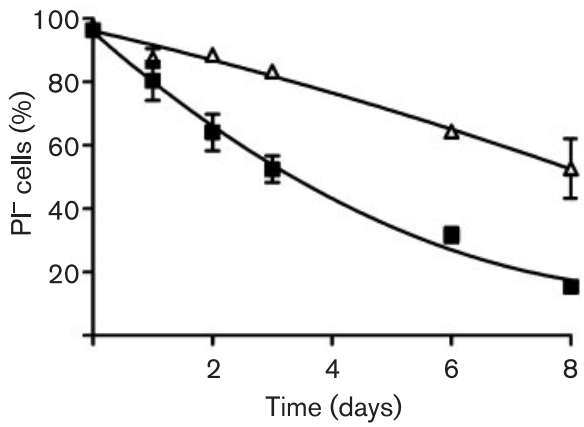

(c)

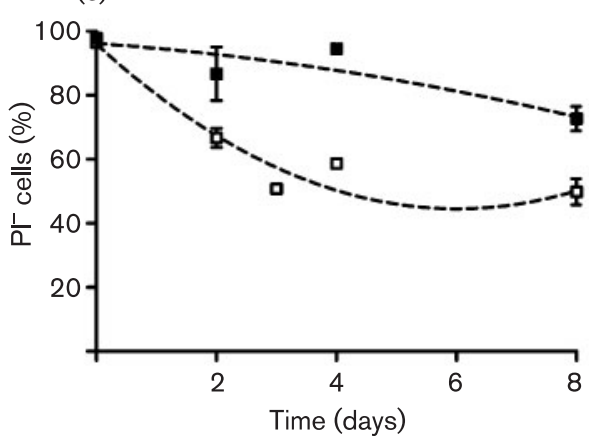

(b)

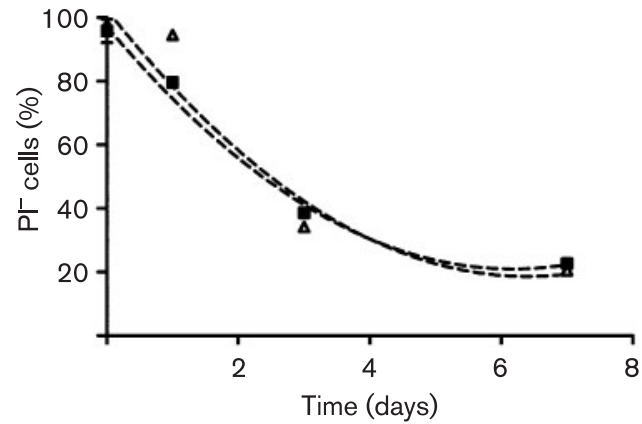

(d)

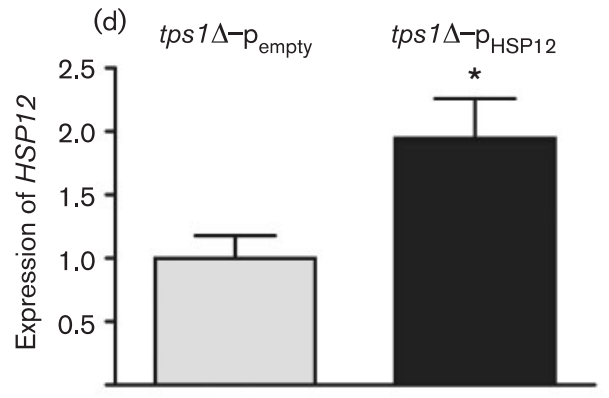

Fig. 1. (a-c) Cell viability analysis during freezing at $-20{ }^{\circ} \mathrm{C}$ : (a) stationary-phase cells of the wild-type $(\boldsymbol{\square})$ and $h s p 12 \Delta(\triangle)$ strains; (b) exponential-phase cells of the wild-type $(\boldsymbol{\square})$ and $h s p 12 \Delta(\triangle)$ strains; and (c) tps $1 \Delta$-transformed strains. Cells of the BY4742 (wild-type) and corresponding mutant strain, $h s p 12 \Delta$, were grown in YPD at $30{ }^{\circ} \mathrm{C}$ until exponential growth phase $\left(\mathrm{OD}_{640} \approx 0.6\right)(\mathrm{b})$ and stationary growth phase $\left(\mathrm{OD}_{640} \approx 3-4\right)(\mathrm{a})$. Cells of the tps $1 \Delta$ strain transformed with the plasmids

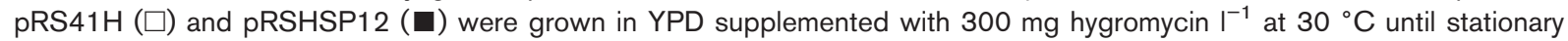
phase $\left(\mathrm{OD}_{640} \approx 3-4\right)(\mathrm{c})$. All strains were then subjected to prolonged storage at $-20^{\circ} \mathrm{C}$. Viability of the cells during freezing was determined by PI exclusion as measured by flow cytometry. In (a) the differences between strains are extremely significant $(P<0.0001)$; in (c) differences between strains were very significant $(P=0.0032)$. Statistical analysis was performed using a two-way ANOVA test. (d) Expression analysis of HSP12 gene by real-time RT-PCR in the tps $1 \Delta$-transformed strains. Values of $H S P 12$ expression are given as relative expression (RE), calibrated with respect to the tps $1 \Delta$ strain harbouring the empty vector.

uptake of exogenous trehalose (which comes from the yeast extract used to make the culture medium; Plourde-Owobi et al., 1999) by the AGT1-encoded transporter (De Hertogh et al., 2006), we also determined the trehalose content of the transformed tps $1 \Delta-\mathrm{p}_{\text {empty }}$ and $t p s 1 \Delta-\mathrm{p}_{\mathrm{HSP} 12}$ strains. Intracellular trehalose content was residual and similar in

Table 2. Intracellular trehalose concentration in stationary phase cells of the strains under study

The values represent mean \pm SD from five experiments.

\begin{tabular}{|c|c|}
\hline Strain & {$[\text { Trehalose }]_{\mathrm{IN}}\left[\mathrm{mg}(\mathrm{g} \text { cells })^{-1}\right]$} \\
\hline Wild-type & $35.3 \pm 3.4$ \\
\hline$h s p 12 \Delta$ & $54.2 \pm 5.6$ \\
\hline$t p s 1 \Delta-\mathrm{p}_{\mathrm{HSP} 12}$ & $5.4 \pm 0.6$ \\
\hline tps $1 \Delta-\mathrm{p}_{\text {empty }}$ & $7.7 \pm 0.6$ \\
\hline
\end{tabular}

both strains $\left[7.7\right.$ and $5.4 \mathrm{mg}(\mathrm{g} \text { cells })^{-1}$ respectively, Table 2], therefore effectively removing influences of trehalose on strain properties. The expression of HSP12 in this strain was confirmed by real-time RT-PCR. As can be seen in Fig. $1(\mathrm{~d})$, the tps $1 \Delta-\mathrm{p}_{\mathrm{HSP} 12}$ strain showed a significant increase in expression of the HSP12 gene when compared with the $t p s 1 \Delta-\mathrm{p}_{\text {empty }}$ strain.

Stationary-phase cells of $t p s 1 \Delta-\mathrm{p}_{\text {empty }}$ and $t p s 1 \Delta-\mathrm{p}_{\mathrm{HSP} 12}$ strains were frozen at $-20{ }^{\circ} \mathrm{C}$ and viability was determined over time. The tps1 1 strain overexpressing HSP12 showed an increase in resistance to freezing when compared to the strain harbouring the empty vector (Fig. 1c).

\section{Heat-stress tolerance is also increased in an HSP12-overexpressing strain}

Previous work has indicated that mutations in the HSP12 gene did not cause a detectable phenotype under several stress conditions, including heat stress (Praekelt \& 
Meacock, 1990; Varela et al., 1995). To investigate if overexpression of the HSP12 gene could also influence heat-shock response in the TPS1 null mutant, we analysed viability of $t p s 1 \Delta-\mathrm{p}_{\mathrm{empty}}$ and $t p s 1 \Delta-\mathrm{p}_{\mathrm{HSP} 12}$ strains in response to a temperature shift from 26 to $50{ }^{\circ} \mathrm{C}$. When we assessed this system with reduced intracellular trehalose, we observed that the strain overexpressing HSP12 showed an increased resistance to heat-shock stress when compared with the strain harbouring the empty vector (Fig. 2a), supporting the idea that Hsp12p effectively contributes to heat-shock resistance.

\section{Increase of intracellular trehalose content in the hsp12 1 strain is not due to increased expression of TPS1}

We next addressed whether HSP12 could directly affect TPS1 expression, which could be responsible for the observed differences in the intracellular trehalose levels. In order to determine if increase in trehalose content in the hsp12 1 strain was due to an induction of TPS1 expression, we measured TPS1 mRNA levels by real-time RT-PCR in wild-type and $h s p 12 \Delta$ strains. The data showed no significant differences in the expression of TPS1 in the two strains (Fig. 2b).

\section{HSP12 deletion does not affect trehalose mobilization but reduces the heat-induced increase of intracellular trehalose concentration}

The higher trehalose concentration in the $h s p 12 \Delta$ strain could also result from a decreased removal by trehalase, as found for the hsp1044 strain (Iwahashi et al., 1998). We next tried to evaluate if HSP12 deletion could originate defects in trehalose mobilization upon different stimuli For that purpose, we examined the intracellular trehalose concentration in stationary-phase cells of both strains, after a glucose pulse or a temperature shift to $50{ }^{\circ} \mathrm{C}$. Trehalase is activated under both conditions, originating a rapid decrease of intracellular trehalose concentration (Carrillo et al., 1992; Thevelein, 1984, 1991). The results showed that there were no significant differences in trehalose degradation over time, either after a glucose pulse or during incubation at $50{ }^{\circ} \mathrm{C}$ (Fig. 3a, b and c).

To determine if deletion of HSP12 would also increase trehalose accumulation during a mild heat treatment, we grew wild-type and $h$ sp $12 \Delta$ cells at $25{ }^{\circ} \mathrm{C}$ until stationary phase and then subjected them to incubation at $37^{\circ} \mathrm{C}$. As shown in Fig. 3(d), the temperature shift from 25 to $37^{\circ} \mathrm{C}$ caused a rise of about fourfold in the wild-type strain, in accordance with previous research reported by Parrou et al. (1997). In contrast, the $h s p 12 \Delta$ strain displayed only a 1.5 fold increase in trehalose content (Fig. 3e). The results show that, contrary to what happens upon entrance into stationary phase, where the trehalose accumulation is increased, the $h s p 12 \Delta$ strain shows a decreased capacity to accumulate trehalose upon mild heat stress.

\section{DISCUSSION}

In this paper we report that disruption of the cold-stressinducible HSP12 gene does not result in increased sensitivity to freezing storage. Our results point to a redundant role for Hsp12p under freezing conditions and identify trehalose as the cell component that is able to replace its functions under such conditions. In fact, when the intracellular trehalose content was decreased to residual (a)

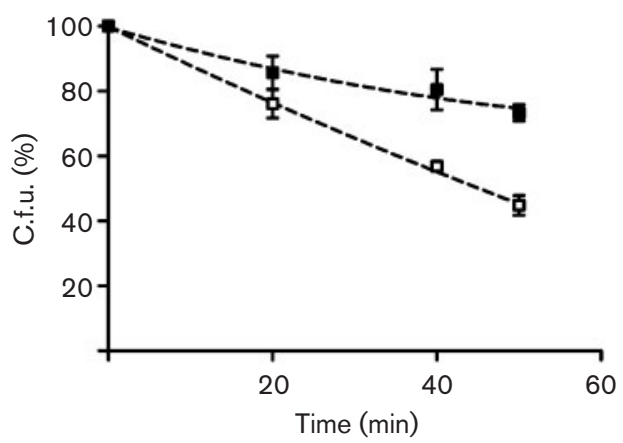

(b)

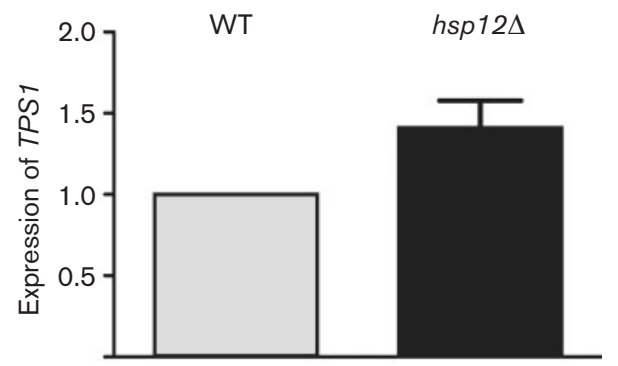

Fig. 2. Heat-shock tolerance at $50{ }^{\circ} \mathrm{C}$ of $t p s 1 \Delta$-transformed strains. (a) Effect of heat shock on cell viability of tps $1 \Delta$ strains transformed with the empty plasmid $(\square)$ and HSP12-expressing plasmid ( $\square$ ). The cells of both strains were grown in YPD supplemented with $300 \mathrm{mg}$ hygromycin $\mathrm{I}^{-1}$ at $25{ }^{\circ} \mathrm{C}$ until stationary phase $\left(\mathrm{OD}_{640} \approx 3-4\right)$. Cells were then diluted to $\mathrm{OD}_{640} 1$ and subjected to a temperature shift from 25 to $50{ }^{\circ} \mathrm{C}$. Viability of the cells was determined by c.f.u., at the indicated times. Two-way ANOVA analysis revealed that differences between strains were extremely significant $(P<0.0001)$. (b) Real-time RTPCR measuring expression of TPS1. Expression was measured in wild-type and $h s p 12 \Delta$ and relative expression (RE) values are shown. Differences between wild-type and $h s p 12 \Delta$ strains were not significant $(P=0.13)$. Comparisons between strains were performed by an unpaired $t$-test. 
(a)

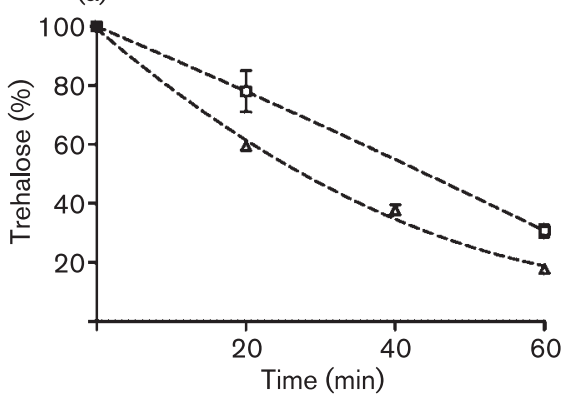

(d)

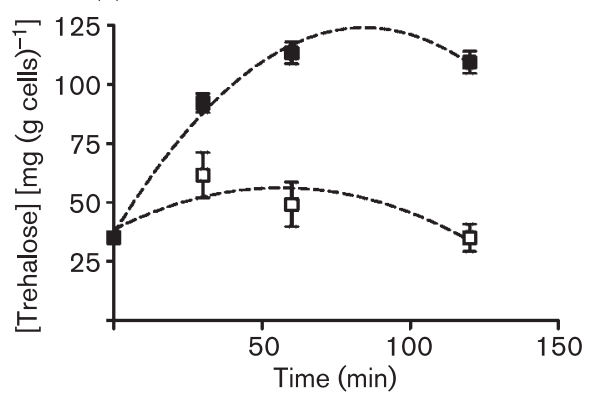

(b)

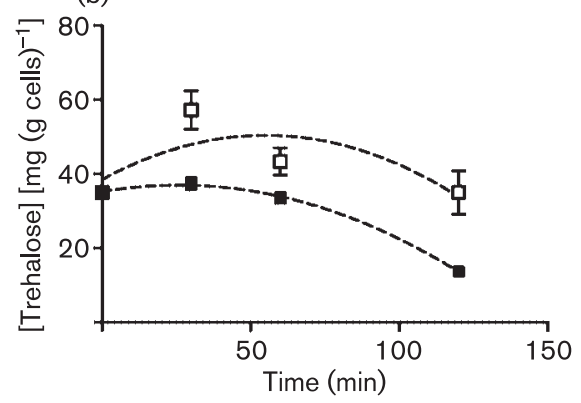

(e) (c)

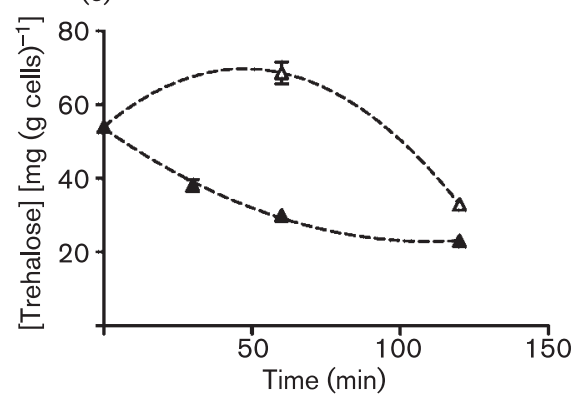

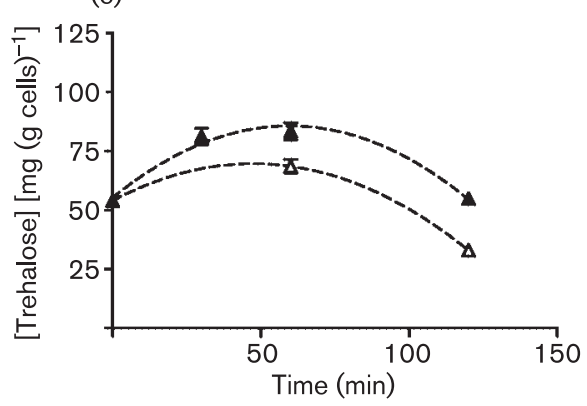

Fig. 3. Intracellular trehalose concentration, over time. (a) After a glucose pulse. Yeast cells of BY4742 ( $\square)$ and $h s p 12 \Delta(\triangle)$ strains were grown in YPD at $30{ }^{\circ} \mathrm{C}$ until stationary phase, and transferred to fresh YPD medium (glucose pulse). Initial values of intracellular trehalose concentration were: [trehalose $]_{\mathrm{BY} 4742}=35 \mathrm{mg}(\mathrm{g} \mathrm{cells})^{-1}$ and $[\text { trehalose }]_{h s p 12 \Delta}=54 \mathrm{mg}(\mathrm{g} \mathrm{cells})^{-1}$. Samples were taken at the indicated times, and trehalose was extracted as described previously in Methods. (b) After heat shock at $50{ }^{\circ} \mathrm{C}$ in the wild-type strain. (c) After heat shock at $50{ }^{\circ} \mathrm{C}$ in the $h s p 12 \Delta$ strain. Cells were grown in YPD until stationary phase and exposed to a temperature shift from 25 to $50{ }^{\circ} \mathrm{C}$. Open symbols are for the control condition at $25{ }^{\circ} \mathrm{C}$, and filled symbols are for the $50{ }^{\circ} \mathrm{C}$ experiment. (d) After heat shock at $37{ }^{\circ} \mathrm{C}$ for wild-type strain. (e) After heat shock at $37{ }^{\circ} \mathrm{C}$ for $h s p 12 \Delta$. Cells were grown in YPD at $25^{\circ} \mathrm{C}$ until stationary phase and exposed to a temperature shift from 25 to $37{ }^{\circ} \mathrm{C}$. Open symbols are for the control conditions at $25^{\circ} \mathrm{C}$, and filled symbols are for the $37{ }^{\circ} \mathrm{C}$ experiments.

levels by TPS1 deletion, an increase in freezing resistance was observed after HSP12 overexpression. Hsp12p has been described to localize at both the cytosol and the plasma membrane (Sales et al., 2000), and extracellularly at the cell wall (Motshwene et al., 2004). Using a model liposome system, it was also shown that Hsp12p acts in a similar way to trehalose in the protection of membrane integrity against desiccation (Sales et al., 2000). Taking into account that loss of cell viability under freezing conditions depends directly on the capacity of yeast cells to preserve their membrane integrity (Alves-Araújo et al., 2004), the results suggest that the protection role of Hsp12p during freezing storage is most probably exerted at the plasma membrane level.

Using the tps $1 \Delta-\mathrm{p}_{\mathrm{HSP} 12}$ strain, we could also show an increase in heat-shock resistance by HSP12 overexpression, demonstrating that Hsp12p can also in fact contribute to heat resistance.

Deletion of HSP12 led to an increase in intracellular trehalose content, which was not accompanied by a significant induction of the TPS1 gene, or by a decreased capacity for trehalose mobilization. Our results support the interpretation that such an increase may result from activation of trehalose-6-phosphate synthase. This is different from what was found for HSP104 deletion, where the observed increase of trehalose content was attributed to a decrease in both neutral trehalase and trehalose-6phosphate synthase activities (Iwahashi et al., 1998).

Although absence of HSP12 led to higher induction of trehalose accumulation upon entry into stationary phase, it decreased the ability of the yeast cells to accumulate high levels of trehalose in response to stress by mild heat shock. These results suggest that Hsp12p may have a role in the induction of trehalose accumulation in response to heat shock.

In conclusion, by overexpressing HSP 12 in a tps $1 \Delta$ strain, we could show that Hsp12p contributes to both freezing and heat resistance, and that its protective role during freezing storage is interchangeable with that of trehalose. Moreover, the tps $1 \Delta$-pHSP12 system developed may prove useful to assess the individual contribution of Hsp12p in other conditions where it shares roles with trehalose.

\section{ACKNOWLEDGEMENTS}

The authors are grateful to Christof Taxis and Michael Knop from EMBL, Cell Biology and Biophysics Unit, Meyerhofstr, Heidelberg, 
Germany, for kindly providing the plasmid vector pRS41H, and to Peter Piper for helpful discussion and suggestions. A.P. was supported by PhD fellowships from BD/13282/2003, Fundação para a Ciência e Tecnologia, Portugal.

\section{REFERENCES}

Alves-Araújo, C., Almeida, M. J., Sousa, M. J. \& Leão, C. (2004). Freeze tolerance of the yeast Torulaspora delbrueckii: cellular and biochemical basis. FEMS Microbiol Lett 240, 7-14.

Attfield, P. V. (1987). Trehalose accumulates in Saccharomyces cerevisiae during exposure to agents that induce heat shock response. FEBS Lett 225, 259-263.

Borovskii, G. B., Stupnikova, I. V., Antipina, A. I., Vladimirova, S. V. \& Voinikov, V. K. (2002). Accumulation of dehydrin-like proteins in the mitochondria of cereals in response to cold, freezing, drought and ABA treatment. BMC Plant Biol 2, 5.

Carrillo, D., Vicente-Soler, J. \& Gacto, M. (1992). Activation of neutral trehalase by fermentable sugars and cAMP in the fission yeast Schizosaccharomyces pombe. FEMS Microbiol Lett 98, 61-66.

De Hertogh, B., Hancy, F., Goffeau, A. \& Baret, P. V. (2006). Emergence of species-specific transporters during evolution of the hemiascomycete phylum. Genetics 172, 771-781.

Diniz-Mendes, L., Bernardes, E., de Araujo, P. S., Panek, A. D. \& Paschoalin, V. M. (1999). Preservation of frozen yeast cells by trehalose. Biotechnol Bioeng 65, 572-578.

Fujita, K., Kawai, R., Iwahashi, H. \& Komatsu, Y. (1998). Hsp104 responds to heat and oxidative stress with different intracellular localization in Saccharomyces cerevisiae. Biochem Biophys Res Commun 248, 542-547.

Hino, A., Mihara, K., Nakashima, K. \& Takano, H. (1990). Trehalose levels and survival ratio of freeze-tolerant versus freeze-sensitive yeasts. Appl Environ Microbiol 56, 1386-1391.

Homma, T., Iwahashi, H. \& Komatsu, Y. (2003). Yeast gene expression during growth at low temperature. Cryobiology 46, 230-237.

Hottiger, T., Boller, T. \& Wiemken, A. (1987). Rapid changes of heat and desiccation tolerance correlated with changes of trehalose content in Saccharomyces cerevisiae cells subjected to temperature shifts. FEBS Lett 220, 113-115.

Hottiger, T., Boller, T. \& Wiemken, A. (1989). Correlation of trehalose content and heat resistance in yeast mutants altered in the RAS/ adenylate cyclase pathway: is trehalose a thermoprotectant? FEBS Lett 255, 431-434.

Inoue, H., Nojima, H. \& Okayama, H. (1990). High efficiency transformation of Escherichia coli with plasmids. Gene 96, 23-28.

Iwahashi, H., Obuchi, K., Fujii, S. \& Komatsu, Y. (1997). Barotolerance is dependent on both trehalose and heat shock protein 104 but is essentially different from thermotolerance in Saccharomyces cerevisiae. Lett Appl Microbiol 25, 43-47.

Iwahashi, H., Nwaka, S., Obuchi, K. \& Komatsu, Y. (1998). Evidence for the interplay between trehalose metabolism and Hsp104 in yeast. Appl Environ Microbiol 64, 4614-4617.

Jules, M., Beltran, G., Francois, J. \& Parrou, J. L. (2008). New insights into trehalose metabolism by Saccharomyces cerevisiae: NTH2 encodes a functional cytosolic trehalase, and deletion of TPS1 reveals Ath1pdependent trehalose mobilization. Appl Environ Microbiol 74, 605614.

Kandror, O. \& Goldberg, A. L. (1997). Trigger factor is induced upon cold shock and enhances viability of Escherichia coli at low temperatures. Proc Natl Acad Sci U S A 94, 4978-4981.
Kandror, O., DeLeon, A. \& Goldberg, A. L. (2002). Trehalose synthesis is induced upon exposure of Escherichia coli to cold and is essential for viability at low temperatures. Proc Natl Acad Sci U S A 99, 97279732.

Kandror, O., Bretschneider, N., Kreydin, E., Cavalieri, D. \& Goldberg, A. L. (2004). Yeast adapt to near-freezing temperatures by STRE/ Msn2,4-dependent induction of trehalose synthesis and certain molecular chaperones. Mol Cell 13, 771-781.

Kuenzi, M. T. \& Fiechter, A. (1972). Regulation of carbohydrate composition of Saccharomyces cerevisiae under growth limitation. Arch Mikrobiol 84, 254-265.

Lillie, S. H. \& Pringle, J. R. (1980). Reserve carbohydrate metabolism in Saccharomyces cerevisiae: responses to nutrient limitation. J Bacteriol 143, 1384-1394.

Motshwene, P., Karreman, R., Kgari, G., Brandt, W. \& Lindsey, G. (2004). LEA (late embryonic abundant)-like protein Hsp 12 (heatshock protein 12) is present in the cell wall and enhances the barotolerance of the yeast Saccharomyces cerevisiae. Biochem J 377, 769-774.

Mtwisha, L., Brandt, W., McCready, S. \& Lindsey, G. G. (1998). HSP 12 is a LEA-like protein in Saccharomyces cerevisiae. Plant Mol Biol 37, 513-521.

Mumberg, D., Muller, R. \& Funk, M. (1995). Yeast vectors for the controlled expression of heterologous proteins in different genetic backgrounds. Gene 156, 119-122.

Murata, Y., Homma, T., Kitagawa, E., Momose, Y., Sato, M. S., Odani, M., Shimizu, H., Hasegawa-Mizusawa, M., Matsumoto, R. \& other authors (2006). Genome-wide expression analysis of yeast response during exposure to 4 degrees C. Extremophiles 10, 117-128.

NDong, C., Danyluk, J., Wilson, K. E., Pocock, T., Huner, N. P. \& Sarhan, F. (2002). Cold-regulated cereal chloroplast late embryogenesis abundant-like proteins. Molecular characterization and functional analyses. Plant Physiol 129, 1368-1381.

Odani, M., Komatsu, Y., Oka, S. \& Iwahashi, H. (2003). Screening of genes that respond to cryopreservation stress using yeast DNA microarray. Cryobiology 47, 155-164.

Panek, A. D. (1975). Trehalose synthesis during starvation of Baker's yeast. Appl Microbiol Biotechnol 2, 39-46.

Parrou, J. L., Teste, M. A. \& Francois, J. (1997). Effects of various types of stress on the metabolism of reserve carbohydrates in Saccharomyces cerevisiae: genetic evidence for a stress-induced recycling of glycogen and trehalose. Microbiology 143, 1891-1900.

Plourde-Owobi, L., Durner, S., Parrou, J. L., Wieczorke, R., Goma, G. \& Francois, J. (1999). AGT1, encoding an alpha-glucoside transporter involved in uptake and intracellular accumulation of trehalose in Saccharomyces cerevisiae. J Bacteriol 181, 3830-3832.

Plourde-Owobi, L., Durner, S., Goma, G. \& Francois, J. (2000). Trehalose reserve in Saccharomyces cerevisiae: phenomenon of transport, accumulation and role in cell viability. Int $J$ Food Microbiol 55, 33-40.

Praekelt, U. M. \& Meacock, P. A. (1990). HSP12, a new small heat shock gene of Saccharomyces cerevisiae: analysis of structure, regulation and function. Mol Gen Genet 223, 97-106.

Prudencio, C., Sansonetty, F. \& Corte-Real, M. (1998). Flow cytometric assessment of cell structural and functional changes induced by acetic acid in the yeasts Zygosaccharomyces bailii and Saccharomyces cerevisiae. Cytometry 31, 307-313.

Randez-Gil, F., Sanz, P. \& Prieto, J. A. (1999). Engineering baker's yeast: room for improvement. Trends Biotechnol 17, 237-244.

Sales, K., Brandt, W., Rumbak, E. \& Lindsey, G. (2000). The LEA-like protein HSP 12 in Saccharomyces cerevisiae has a plasma membrane 
location and protects membranes against desiccation and ethanolinduced stress. Biochim Biophys Acta 1463, 267-278.

Sambrook, J., Fritsch, E. F.\& Maniatis, T. (1989). Molecular Cloning: $a$ Laboratory Manual, 2nd edn. Cold Spring Harbor, NY: Cold Spring Harbor Laboratory.

Sanger, F. \& Coulson, A. R. (1975). A rapid method for determining sequences in DNA by primed synthesis with DNA polymerase. J Mol Biol 94, 441-448.

Schiestl, R. H. \& Gietz, R. D. (1989). High efficiency transformation of intact yeast cells using single stranded nucleic acids as a carrier. Curr Genet 16, 339-346.

Seymour, I. J. \& Piper, P. W. (1999). Stress induction of HSP30, the plasma membrane heat shock protein gene of Saccharomyces cerevisiae, appears not to use known stress-regulated transcription factors. Microbiology 145, 231-239.

Singer, M. A. \& Lindquist, S. (1998). Thermotolerance in Saccharomyces cerevisiae: the Yin and Yang of trehalose. Trends Biotechnol 16, 460-468.

Stone, R. L., Matarese, V., Magee, B. B., Magee, P. T. \& Bernlohr, D. A. (1990). Cloning, sequencing and chromosomal assignment of a gene from Saccharomyces cerevisiae which is negatively regulated by glucose and positively by lipids. Gene $96,171-176$.

Taxis, C. \& Knop, M. (2006). System of centromeric, episomal, and integrative vectors based on drug resistance markers for Saccharomyces cerevisiae. Biotechniques 40, 73-78.

Thevelein, J. M. (1984). Regulation of trehalose mobilization in fungi. Microbiol Rev 48, 42-59.
Thevelein, J. M. (1991). Fermentable sugars and intracellular acidification as specific activators of the RAS-adenylate cyclase signalling pathway in yeast: the relationship to nutrient-induced cell cycle control. Mol Microbiol 5, 1301-1307.

Van Dijck, P., Colavizza, D., Smet, P. \& Thevelein, J. M. (1995). Differential importance of trehalose in stress resistance in fermenting and nonfermenting Saccharomyces cerevisiae cells. Appl Environ Microbiol 61, 109-115.

Varela, J. C., Praekelt, U. M., Meacock, P. A., Planta, R. J. \& Mager, W. H. (1995). The Saccharomyces cerevisiae HSP12 gene is activated by the high-osmolarity glycerol pathway and negatively regulated by protein kinase A. Mol Cell Biol 15, 6232-6245.

Wenzel, T. J., Teunissen, A. W. \& de Steensma, H. Y. (1995). PDA1 mRNA: a standard for quantitation of mRNA in Saccharomyces cerevisiae superior to ACT1 mRNA. Nucleic Acids Res 23, 883-884.

Wiemken, A. (1990). Trehalose in yeast, stress protectant rather than reserve carbohydrate. Antonie Van Leeuwenhoek 58, 209-217.

Zarka, D. G., Vogel, J. T., Cook, D. \& Thomashow, M. F. (2003). Cold induction of Arabidopsis CBF genes involves multiple ICE (inducer of $\mathrm{CBF}$ expression) promoter elements and a cold-regulatory circuit that is desensitized by low temperature. Plant Physiol 133, 910-918.

Zhang, L., Ohta, A., Takagi, M. \& Imai, R. (2000). Expression of plant group 2 and group 3 lea genes in Saccharomyces cerevisiae revealed functional divergence among LEA proteins. J Biochem 127, 611-616.

Edited by: D. Burke 